\title{
Thin films of copper phthalocyanine deposited by solution processing methods
}

\author{
Hubert Gojzewski $^{1, *}$, FAtemeh Ghani ${ }^{2}$, MirosŁaw Szybowicz ${ }^{1}$ \\ ${ }^{1}$ Faculty of Materials Engineering and Technical Physics, Poznan University of Technology, Piotrowo 3, 60965 Poznan, \\ Poland \\ ${ }^{2}$ Department of Theory and Bio-Systems, Max Planck Institute of Colloids and Interfaces, Am Mühlenberg 1 Golm, 14476 \\ Potsdam, Germany
}

\begin{abstract}
In this work, we show and discuss the surface structure picture of copper phthalocyanine $(\mathrm{CuPc})$ thin films deposited from trifluoroacetic acid (TFA) solvent onto silicon substrates at ambient conditions by four solution processing methods, namely drop-casting, dip-coating, spin-casting and spray-coating. The CuPc films were studied by AFM, as the main technique, and complemented by micro-Raman spectroscopy. Essentially, such thin films consist of CuPc molecular nanoribbons of a fixed $\sim 1 \mathrm{~nm}$ thickness. CuPc molecules are arranged in an in-plane direction and formed in stacks under a defined tilt angle with respect to the substrate surface (monolayer) or underlying CuPc layer (multilayer). The film morphology takes various forms depending on the solution concentration, number of layers, and the deposition method. For instance, the morphology varies from very wide $(\sim 600 \mathrm{~nm})$ but flat $(\sim 1 \mathrm{~nm})$ ribbons for films prepared by dip-coating to crystallized rod-like features (multi-layered ribbons) when obtained by spray-coating. The factors studied in this paper should be taken into consideration in designing and controlling the criteria for rigorous $\mathrm{CuPc}$ film architecture.
\end{abstract}

Keywords: molecular structure; growth; copper phthalocyanine; solution processing methods; atomic force microscopy

\section{Introduction}

Thin films represent essential system where one type of material is deposited onto a target surface of different chemical compositions and physical topography [1]. The surface coverage can be obtained either by dry (sputtering, physical vapor deposition, etc.) or wet (solution processing methods) processes. The method of choice, processing parameters, and choice of substrate, strictly determine physicochemical properties of the thin films and their potential application [2, 3]. While dry processing usually requires advanced and expensive vacuum-based facilities, wet methods are low-cost, easy to access and handle, and relatively wastefree [4]. Despite the technological simplicity, solution processing methods distribute homogeneously compounds in the final film with an accurate control of thickness. Thus, solution processing methods arouse a vast interest in science, technology,

*E-mail: hubert.gojzewski@ put.poznan.pl and industry [4, 5]. Especially worthy of note are drop-casting, dip-coating, spin-casting and spraycoating. The application of drop-casting is industrially limited due to the low (accessible) coating area and the deposition control. This method, however, is relevant for surface preparation, e.g., for biomaterials [6] and nanoparticles [7]. Dip-coating has a broader application value, for instance, in sol-gel process [8], for ceramic, plastic and metal coatings [9, 10]. Applications of spin-casting and spray-coating seem to be industrially dominant. For spin-casting, one can mention, e.g., protective coatings against corrosion or UV light [11], solar cells [12], sensors [13], various microelectronics applications [14-16], displays and LEDs [17, 18]. Spraying is commonly used for surface coatings $[19,20]$ and their functionalization [21, 22], particle formation or encapsulation [23, 24], and it is applied to produce organic solar cells [25] as well as other electronic devices [26, 27].

Some metallophthalocyanines have attracted considerable attention due to their unique optical 
and electrical properties and thermal stability [28]. Films composed of copper phthalocyanine $(\mathrm{CuPc})$ molecules have become a leading material in metallophthalocyanines for electronic and optoelectronic devices [29-35]. Recently, CuPc was used collectively with graphene and carbon nanotubes for innovative photovoltaic applications [36-38]. These studies demonstrated that the future perspective for $\mathrm{CuPc}$ film use is immensely optimistic indeed by envisaging new efficient materials and their applicability. Certainly, controlling and understanding the process of molecular growth and the film architecture are the ways to design sophisticated materials with the fine-tuned properties.

While CuPc films obtained in a dry deposition process have been well studied in the literature [39-42], these obtained in a wet deposition process remain fragmented and incomplete [4347]. This difficulty is dictated by the poor solubility of CuPc in commonly used solvents [44-48]. In the previous work, we aimed to propose a nucleation and growth model of $\mathrm{CuPc}$ molecules deposited on planar surfaces from low concentrated, trifluoroacetic acid (TFA) based, solutions [45]. In this work we produced $\mathrm{CuPc}$ films prepared by drop-casting, dip-coating, spin-casting and spraycoating from highly concentrated $\mathrm{CuPc}$ in TFA solutions. We aimed at obtaining high molecular coverage, and to describe and discuss physical differences among the produced films. The surface topography was imaged by means of atomic force microscopy (AFM), and the resulting morphology was analyzed. We studied also the impact of solution rewetting and the result of a long-term annealing on the CuPc molecular order via high spatial resolution Raman mapping of micro-sized areas. The data shown and described herein may be essential to establish design criteria of the CuPc molecular architecture.

\section{Materials, methods, and sample preparation}

\section{CuPc}

CuPc $(>99 \%)$ was purchased from Minakem Leuna GmbH (Germany). Trifluoroacetic acid (TFA, purity >99 \%) was purchased from Sigma-Aldrich. Initially, a stock solution $1.7 \times 10^{-3} \mathrm{~mol} \cdot \mathrm{L}^{1} \mathrm{CuPc}$ in TFA (near saturation) was prepared and further diluted in TFA to obtain solutions of various concentrations. All samples were stirred for approximately $12 \mathrm{~h}$ to $24 \mathrm{~h}$ and immediately used for deposition to avoid protonation of $\mathrm{Cu}$ in the phthalocyanine.

\section{Drop-, dip-, spin-, and spray casting/coating deposition}

Substrate. Prior the deposition, silicon wafers (Silchem, Germany) that contained an artificially grown oxide layer $(\sim 300 \mathrm{~nm})$ were cut into approximately $1 \mathrm{~cm} \times 1 \mathrm{~cm}$ pieces and cleaned with due diligence to remove organic and non-organic contaminations. The wafers were immersed in an acetone and ethanol ultrasonic bath for $10 \mathrm{~min}$, each solvent separately, and afterwards extensively rinsed several times with purified and deionized water. Such pre-cleaned substrates were submerged in Piranha solution, i.e. a mixture of hydrogen peroxide (35\% $\mathrm{H}_{2} \mathrm{O}$ solution) and sulfuric acid (99\%) (1:3), for $30 \mathrm{~min}$ and subsequently washed several times with purified and deionized water. The substrates were dried under nitrogen flow and used directly for deposition. All depositions were performed at room temperature in air or $\mathrm{N}_{2}$ atmosphere, depending on the specific method. The prepared samples were measured without undue delay. Drop-casting. A $15 \mu \mathrm{L}$-drop of CuPc/TFA $1.5 \times$ $10^{-3} \mathrm{~mol} \cdot \mathrm{L}^{-1}$ solution was placed with a pipette onto the center of the substrate and allowed for liquid spreading and film drying in air.

Dip-coating. The following $\mathrm{CuPc} / \mathrm{TFA}$ solution concertations were used: $0.5 \times 10^{-3} \mathrm{~mol} \cdot \mathrm{L}^{-1}$, $1.0 \times 10^{-3} \mathrm{~mol} \cdot \mathrm{L}^{-1}$ and $1.5 \times 10^{-3} \mathrm{~mol} \cdot \mathrm{L}^{-1}$. Dip-coating was performed in air using a dip coater device (Riegler \& Kirstein GmbH, Germany) with a precise immerging system retrofitted with a speed controller. We applied $1 \mathrm{~mm} \cdot \mathrm{s}^{-1}$ of dipping/withdraw velocity; it was found as an optimum speed to avoid capillary and viscose drag regime [49].

Spin-casting. The following CuPc/TFA solution concertations were used: $0.5 \times 10^{-3} \mathrm{~mol} \cdot \mathrm{L}^{-1}$, $0.7 \times 10^{-3} \mathrm{~mol} \cdot \mathrm{L}^{-} 1,1.0 \times 10^{-3} \mathrm{~mol} \cdot \mathrm{L}^{-1}$ and 
$1.5 \times 10^{-3} \mathrm{~mol} \cdot \mathrm{L}^{-1}$. A $15 \mu \mathrm{L}$-drop of the solution was casted onto the rotating substrate in air with the rotation speed of $5000 \mathrm{rpm}$ and spun for $30 \mathrm{~s}$ for solvent evaporation. The SCI and SCE spin coaters from Novocontrol Technologies GmbH (Germany) were used.

For the Raman mapping, the samples were prepared in a standard way (1 drop-processing) as well as with 2 drops-processing (with $30 \mathrm{~s}$ of the interval between the droplets, using solutions of the same concertation). This procedure was implemented to unveil the influence of the rewetting effect, predominantly the molecular re-orientation in the $\mathrm{CuPc}$ films. The $0.7 \times 10^{-3} \mathrm{~mol} \cdot \mathrm{L}^{-1}$ solution concertation was used, which was the lowest to record a decent signal to noise ratio in Raman spectroscopy. A long-term annealing $\left(5 \mathrm{~h}, 150{ }^{\circ} \mathrm{C}\right)$ was thereafter applied to study if the rewetting effect reversed by the annealing.

Spray-coating. The CuPc/TFA solution at concertation of $1.5 \times 10^{-3} \mathrm{~mol} \cdot \mathrm{L}^{-1}$ was sprayed by means of high frequency $(2.4 \mathrm{MHz})$ atomizer (model 241 PGT, Sonaer, Inc., USA) in a homemade Teflon-glass chamber with an adjustable spray-outlet to alter the substrate distance and deposition time. In addition, an independent and commercially non available cooling system was implemented to enable higher continuous atomizer powers, but most of all to keep the sprayed solution temperature constant. Spray droplets were drifted and directed to the substrates by a stream of $\mathrm{N}_{2}$ controlled by two-coupled mass flow controllers (model MF1, MKS, USA). Further details about the setup can be found in the literature [45]. The size of the droplets was not measured explicitly. The initial size of spray droplets $(\sim 1 \mu \mathrm{m})$ was calculated based on the surface tension of TFA and confirmed by the weak light scattering of the spray by a green $(520 \mathrm{~nm})$ laser beam [50]. One spray droplet contained $\sim 3.6 \times 10^{5}$ of $\mathrm{CuPc}$ molecules for the CuPC/TFA solution concentration of $1.5 \times 10^{-3} \mathrm{~mol} \cdot \mathrm{L}^{1}$. Silicon substrates were placed perpendicular to the spray flow, around $50 \mathrm{~mm}$ from the center of the atomization. CuPc/TFA solutions were sprayed for $10 \mathrm{~s}$ under $400 \mathrm{sccm}$ of $\mathrm{N}_{2}$ flow in 1 cycle, $3 \mathrm{cy}-$ cles, and 5 cycles with an interval time of $30 \mathrm{~s}$ between the cycles. The films were dried immediately after spraying in $\mathrm{N}_{2}$ atmosphere.

\section{AFM}

AFM experiments were performed by Bruker Multimode and Dimension 3100 (USA), both retrofitted with NanoScope IIIb controller. The AFM images were obtained in the tapping mode with a standard AFM tips (nominal tip radius $<10 \mathrm{~nm}$ : Olympus, Japan, model OMCLAC 160 TS; Nanoworld, Switzerland, model NCHR; BudgetSensors, Bulgaria, model Tap300-G). All measurements were done in ambient atmosphere in a low-noise acoustic chamber. For the evaluation of the AFM data, SPIP 6.0.1, Gwyddion 2.38, NanoScope Analysis 1.50 were used. To expose the surface texture of the studied samples, three components that define the morphology and topography in the $\mathrm{CuPc}$ films were calculated, i.e. mean roughness $(\mathrm{Ra})$, substrate coverage fraction $\left(\mathrm{S}_{\mathrm{CuPc}}\right)$, and film volume $\left(\mathrm{V}_{\mathrm{CuPc}}\right)$. These components were calculated for the AFM scan size area of $10 \mu \mathrm{m} x$ $10 \mu \mathrm{m}$. Taking into account the morphological and topographical character of the ribbons' structure in the $\mathrm{CuPc}$ films, this area is most favorable to summarize the surface features. The mean roughness provides high reliability in statistical surface measures [51]. The mean roughness is defined by a sum of the absolute height values of all the areas (pixels) above and below the mean line divided by the number of pixels. Roughness measurements were done at three different spots on each CuPc specimen ( 9 values for one specific sample as the samples were triplet, i.e. prepared under the same conditions; exceptions were the drop-coated films due to their non-homogeneous morphological character) and Ra was averaged. Substrate coverage fraction is defined as a ratio of the maximum area covered by the $\mathrm{CuPc}$ molecules above the substrate to the substrate total area (i.e. AFM scan size area). The film volume is defined as the sample volume above the substrate (i.e. entire mono- or multilayer volume). 


\section{Raman mapping}

The Raman scattering spectra of $\mathrm{CuPc}$ films were investigated in the spectral range of $1250 \mathrm{~cm}^{-1}$ to $1700 \mathrm{~cm}^{-1}$. The non-polarized and two types of polarized (for $\mathrm{VV}$ and $\mathrm{VH}$ scattering geometry; Raman surface mapping) Raman spectra were recorded in the backscattering geometry using inVia Renishaw micro-Raman system (UK). As an excitation light, we used the blue line of argon laser operating at $488 \mathrm{~nm}$. The same laser as a source of exciting light was used to study Raman surface mapping. The laser beam was tightly focused on the sample surface through a Leica $\times 50$ LWD (long working distance) microscope objective with numerical aperture equal to 0.5 , leading to a laser beam diameter about $2 \mu \mathrm{m}$. To prevent any damages to the sample, the excitation power was fixed at $1 \mathrm{~mW}$. The position of the microscope objective with respect to the thin layer was piezoelectrically controlled during surface mapping (XY position). The reference position (level 0) was assumed for the laser spot focused on the surface of sample. The obtained Raman maps of surface of the thin layer covered an area of $10 \times 10 \mu \mathrm{m}$ with the step of $1 \mu \mathrm{m}$. The inVia Raman spectrometer allows for recording the Raman spectra with the spatial resolution of about $1 \mu \mathrm{m}[39,52]$.

\section{Results and discussion}

\section{AFM analysis}

Drop-casting. Fig. 1 shows AFM images captured at three different spots for a sample prepared by drop-casting CuPc/TFA $1.5 \times 10^{-3} \mathrm{~mol} \cdot \mathrm{L}^{-1}$ solution onto a $\mathrm{SiO}_{2}$ substrate. $\mathrm{CuPc}$ molecules form ribbons (all spots), with the coverage/arrangement changes over the sample. The structure shown in Fig. 1a is formed by up to three monolayers of narrow ribbons with a monolayer-step height profile $\sim 1 \mathrm{~nm}$, indicating the size of CuPc molecule [53]. The coverage of the first layer, adsorbed directly onto $\mathrm{SiO}_{2}$ substrate, is dominant, while the coverage of the upper layers is smaller, especially the last one (minor). The $\mathrm{CuPc}$ molecules tend to the pyramidal way of growth. Fig. 1b shows a noticeable $\mathrm{CuPc}$ substrate coverage fraction (molecular surface coverage); bunches of $\mathrm{CuPc}$ ribbons with randomly located depressions and large changes in the height profile $(\sim 30 \mathrm{~nm})$. Fig. 1c shows a similar structure, but with a relatively higher substrate coverage fraction. The mean roughness, substrate coverage fraction, and film volume values (also for specimens obtained using others solution processing methods) are shown in Table 1.

Differences in the film morphology arise from inhomogeneous solvent drying along the surface [54]. TFA covers the hydrophilic $\mathrm{SiO}_{2}$ surface almost completely with a contact angle $\sim 0^{\circ}$. Therefore, CuPc/TFA solution spreads immediately on the surface, forming a uniform liquid film. However, as the evaporation rate differs in the center of the drop and at the edges, the capillary flow outward from the center of the drop brings dissolved CuPc molecules to the edge as evaporation proceeds. Evaporation of TFA in liquid film is fast, attaining the evaporation rate of about $0.5 \mu \mathrm{m} \cdot \mathrm{s}^{-1}$ [55]. Additionally, the sample edges indicate instability points resulting from mass transfer along the liquid film due to evaporation rate gradient. These effects influence the final $\mathrm{CuPc}$ film morphology and result in its deprived structure continuity.

Dip-coating. Fig. 2 presents height AFM images of the samples obtained from $0.5 \times 10^{-3} \mathrm{~mol} \cdot \mathrm{L}^{-1}$, $1.0 \times 10^{-3} \mathrm{~mol} \cdot \mathrm{L}^{-1}$ and $1.5 \times 10^{-3} \mathrm{~mol} \cdot \mathrm{L}^{-1}$ $\mathrm{CuPc} / \mathrm{TFA}$ solutions. CuPc forms a mesh-like coverage of long, cambered and interconnected nanoribbons (submonolayer). In all cases the width of the nanoribbons can be controlled by the solution concentration: $\sim 100 \mathrm{~nm}, \sim 180 \mathrm{~nm}$, and $\sim 600 \mathrm{~nm}$ for the monolayers shown in Fig. 2a, Fig. 2b, and Fig. 2c, respectively. The length of interconnected nanoribbons seems to be less influenced by solution concentration (no strict tendency observed), whereas, the height of each layer is constant and equal to $\sim 1 \mathrm{~nm}$, i.e. size of the $\mathrm{CuPc}$ molecule [53]. CuPc molecules are arranged in an in-plane direction and formed in stacks. We also investigated samples prepared from $\mathrm{CuPc} / \mathrm{TFA}$ solution of different concentrations (not shown). For instance, for a concentration lower than 

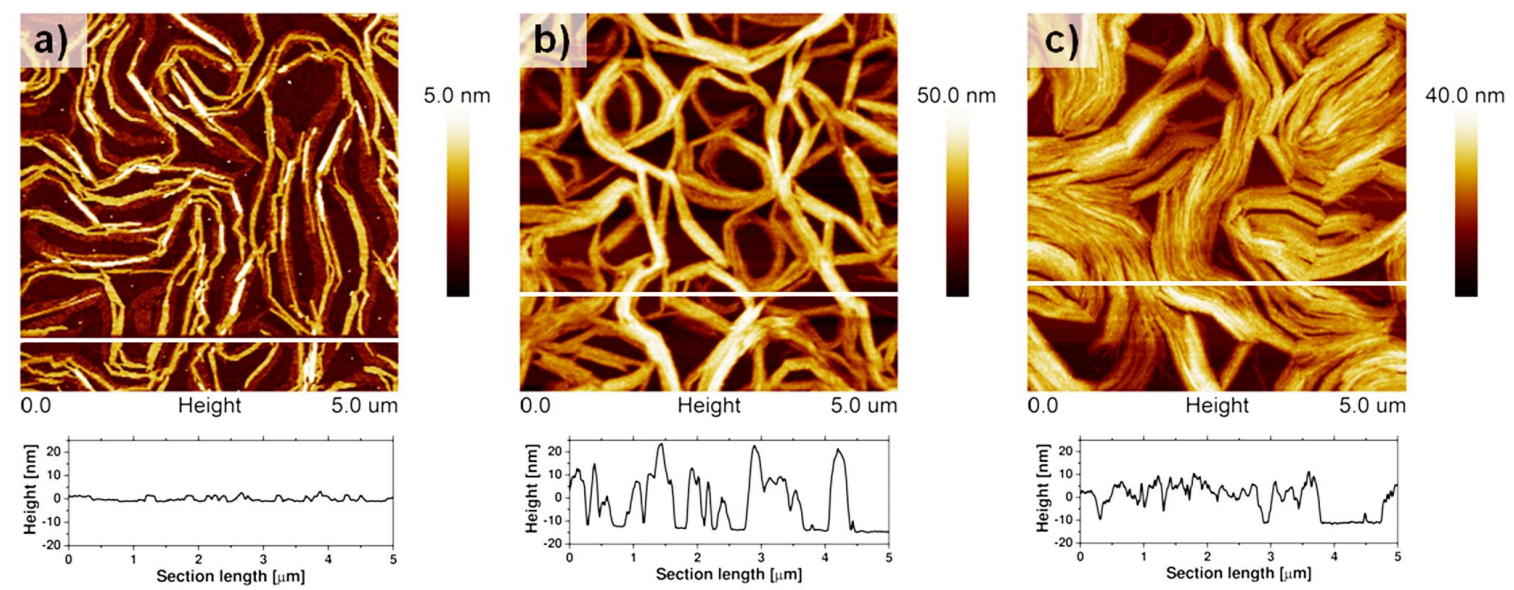

Fig. 1. AFM height images taken at different spots ( $a, b$ and $c)$ of the same sample. The film was prepared by dropcasting $\mathrm{CuPc} / \mathrm{TFA} 1.5 \times 10^{-3} \mathrm{~mol} \cdot \mathrm{L}^{-1}$ solution on $\mathrm{SiO}_{2}$ substrate. White lines represent section lines with their respective section plots. The height scale in the section plots is adjusted to make the data comparable.

$1.0 \times 10^{-5} \mathrm{~mol} \cdot \mathrm{L}^{-1}$, the CuPc mesh is transformed into single (disconnected) ribbons, regularly distributed on the surface. For the solution concentration near the saturation $\left(1.7 \times 10^{-3} \mathrm{~mol} \cdot \mathrm{L}^{-1}\right) \mathrm{CuPc}$ form a bi-layer (second layer is in the initial growth phase).

The evaporation rate in the vicinity of the drying line usually diverges from constant evaporation. This is due to geometrical factors affecting the solvent vapor diffusion from the solution gas-liquid interface [56]. We have observed this effect as well, however, the changes in the nanoribbon width were small, up to $15 \%$ at different spots on the sample, with no changes in the height at all. We attribute such small changes in the film structure to the low amount of material to be transferred from solution onto substrate that results into submonolayer formation, and thus may be influenced by the solvent vapor diffusion.

Spin-casting. The samples were spin-casted at $5000 \mathrm{rpm}$ from CuPc/TFA solutions $0.5 \times 10^{-3} \mathrm{~mol} \cdot \mathrm{L}^{-1}, 1.0 \times 10^{-3} \mathrm{~mol} \cdot \mathrm{L}^{-1}$ and $1.5 \times 10^{-3} \mathrm{~mol} \cdot \mathrm{L}^{-1}$ on $\mathrm{SiO}_{2}$ (Fig. 3). In Fig. 3a, CuPc molecules form interconnected ribbons of different width, typically within the range of $50 \mathrm{~nm}$ to $200 \mathrm{~nm}$, and length of about hundreds of nm, but constant thickness equal to $\sim 1 \mathrm{~nm}$. Dark brown areas between the ribbons represent the bare silicon oxide substrate. The film is a submonolayer. Next two samples show significant changes in the topography and morphology. Submonolayer transforms into a multilayer that includes up to 5 monolayers (3-4 in Fig. $3 \mathrm{~b}$ and 4-5 in Fig. 3c). Here, a complete coverage for a given layer is never achieved due to the interplay between (1) nucleation, (2) diffusive transport, and (3) growth process forced by the anisotropy interactions of the CuPc molecules (Table 1).

Spray-coating. Due to specific technical conditions and the method itself, spray-coating provides variety of CuPc structures of the material deposited on surfaces. The amount of material deposited on the surface is limited by the deposition time, spraygas flow rate (mass flow), solution concentration, and distance between the source and the target (due to the spray chamber geometry). In particular, spray-coating can deliver significantly more material to the substrate than any other solution processing method studied herein. The evaporation process in the spray droplet is controlled by the equilibrium between the liquid phase and the vapor saturation surrounding the droplet, with a major contribution of time of the spray flow (drying time) and type of gas in use. Due to the fact that several deposition scenarios are possible in the system: (1) complete solvent evaporation before 

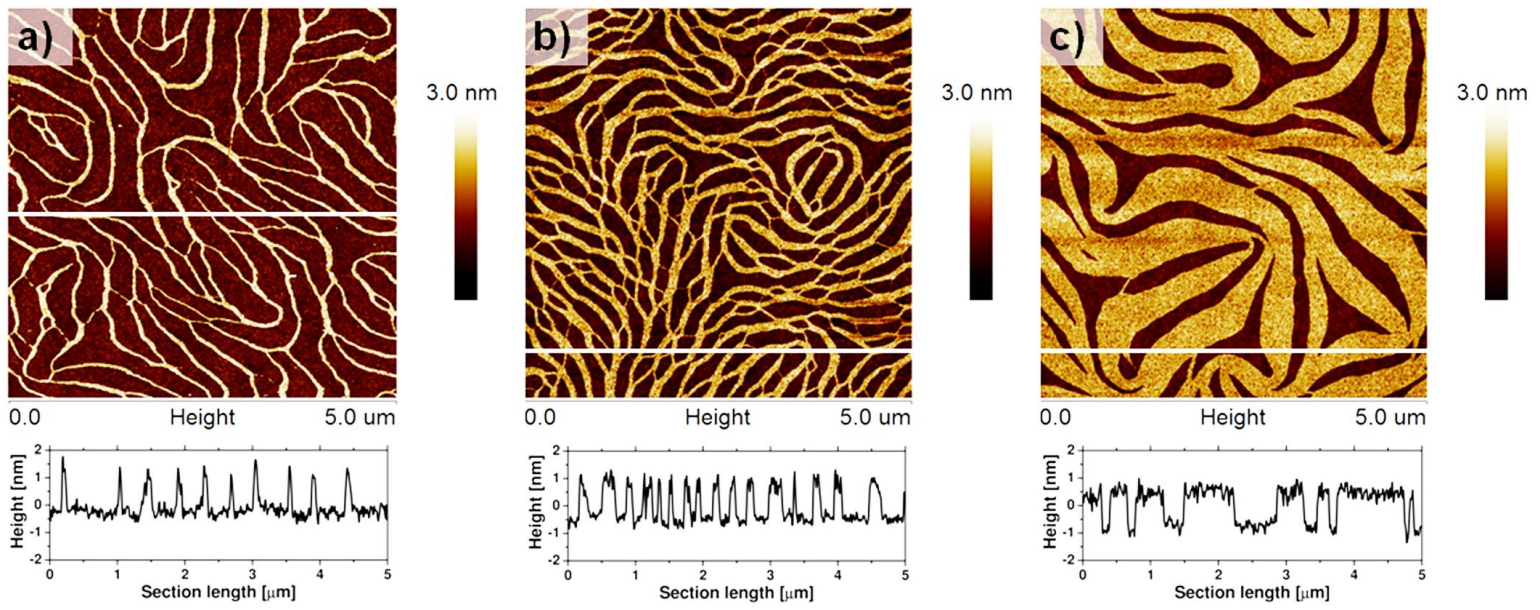

Fig. 2. AFM height images of dip-coated films from $\mathrm{CuPc} / \mathrm{TFA}$ solution on $\mathrm{SiO}_{2}$ substrate at $1 \mathrm{~mm} \cdot \mathrm{s}^{-1}$ of dipping/withdraw velocity. Three solutions of different concentrations were used: $0.5 \times 10^{-3} \mathrm{~mol} \cdot \mathrm{L}^{-1}$ (a), $1.0 \times 10^{-3} \mathrm{~mol} \cdot \mathrm{L}^{-1}$ (b), $1.5 \times 10^{-3} \mathrm{~mol} \cdot \mathrm{L}^{-1}$ (c). White lines represent section lines with their respective section plots. Dark brown parts indicate silicon oxide bare substrate. The height scale in the section plots is adjusted to make the data comparable.
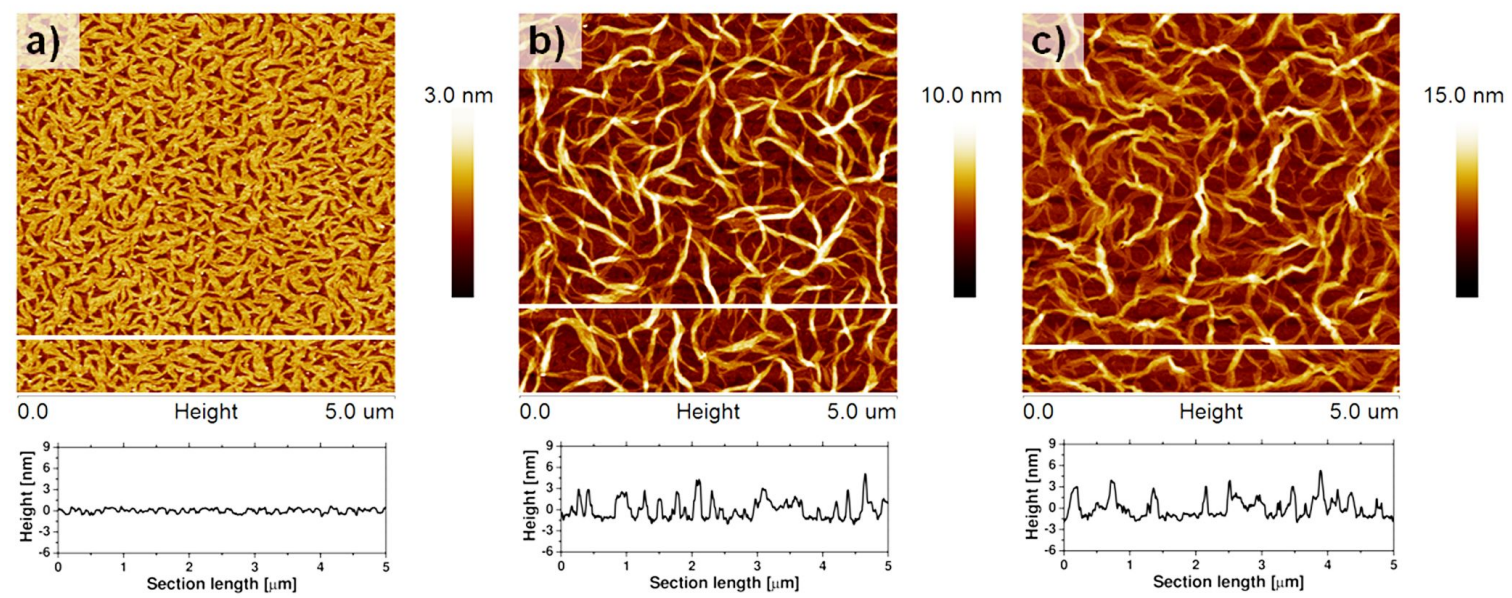

Fig. 3. AFM height images of the films spin-casted from $\mathrm{CuPc} / \mathrm{TFA}$ solution on $\mathrm{SiO}_{2}$ substrate at $5000 \mathrm{rpm}$. Three solutions of different concentrations were used: $0.5 \times 10^{-3} \mathrm{~mol} \cdot \mathrm{L}^{-1}$ (a), $1.0 \times 10^{-3} \mathrm{~mol} \cdot \mathrm{L}^{-1}$ (b), $1.5 \times 10^{-3} \mathrm{~mol} \cdot \mathrm{L}^{-1}$ (c). White lines represent section lines with their respective section plots. Dark brown parts in (a) indicate silicon bare substrate. The height scale in the section plots is adjusted to make the data comparable.

droplet deposition (homogeneous nucleation), (2) deposition of droplets with a supersaturated solution (heterogeneous nucleation), and (3) deposition of droplets with an undersaturated solution (heterogeneous nucleation), we have decided to simplify the experiment to obtain a comparable result to dip- and spin-casting data. Thus, we spraycoated $\mathrm{SiO}_{2}$ substrates with unsaturated solution (i.e. as noted in point 3 above) to let the droplets coalesce at the substrate (liquid film). We performed $10 \mathrm{~s}$ spray deposition in cycles ( 1 cycle, 3 cycles, and 5 cycles) with $30 \mathrm{~s}$ of interval time between 
cycles. This time was found to be suitable to get, in majority, the TFA evaporated from the film.

The multilayer morphology of the film deposited by spray-coating (Fig. 4a) coincidences with this one presented in the Fig. 3c (spin-casting). One should expect noticeable differences in the film structure for sprayed layer as compared to spin-casted, in particular because less dynamics in the film (e.g. centrifugal forces) is present $(\mathrm{CuPc}$ should have more time to diffuse and growth). This fact, however, indicates that such morphology is obtained during solvent evaporation. The features shown in Fig. 4b and Fig. 4c were obtained as an effect of dissolving the existing layer by next cycles of spraying. With a new cycle, more material is delivered to the substrate, leading to supersaturation of the liquid film. Once the liquid film of $\mathrm{CuPc} / \mathrm{TFA}$ solution reaches concentration of $\sim 1.8 \times 10^{-3} \mathrm{~mol} \cdot \mathrm{L}^{-1}$, CuPc precipitation starts in the liquid film $(\mathrm{CuPc}$ aggregates formation in the liquid layer). $\mathrm{CuPc}$ molecules crystallize in large blocks with a sharp crystal edges (rod-like features). This effect is pronounced clearly in Fig. 4c.

We conducted also the spray-coating of silicon oxide substrates with air flow, instead of $\mathrm{N}_{2}$. However, no particular changes in the topography and morphology of the $\mathrm{CuPc}$ film were found.

AFM surface texture analysis. The mean roughness, $\mathrm{Ra}$, the substrate coverage fraction, $\mathrm{S}_{\mathrm{CuPc}}$, and the film volume, $\mathrm{V}_{\mathrm{CuPc}}$, values indicate dissimilarities in the topography and morphology as well as the coverage (Table 1).

For drop-casting, the Ra values diverse at different spots on the sample, from $\sim 1 \mathrm{~nm}$ to $\sim 10 \mathrm{~nm}$, therefore, cannot be averaged. Changes in the $\mathrm{Ra}$ indicate inhomogeneous solvent drying as discussed above. Although the $\mathrm{S}_{\mathrm{CuPc}}$ and $\mathrm{V}_{\mathrm{CuPc}}$ values were found as high, their change at randomly chosen sample spots implies significant morphological (molecular) rearrangement across the sample.

Samples obtained by dip-coating are characterized by the lowest molecular coverage as compared to the films obtained by drop-casting, spin-coating and spraying. $\mathrm{S}_{\mathrm{CuPc}}$ is found from $\sim 18 \%$ to $64 \%$, and maximum $\mathrm{V}_{\mathrm{CuPc}}$ of $0.036 \mu \mathrm{m}^{3}$. Reducing the dipping/withdraw velocity consequences in a minor increase of the $\mathrm{S}_{\mathrm{CuPc}}$ and $\mathrm{V}_{\mathrm{CuPc}}$ values. The mean roughness, $\mathrm{Ra}$, was found to be $0.4 \pm 0.1 \mathrm{~nm}$, $0.6 \pm 0.1 \mathrm{~nm}$, and $0.5 \pm 0.1 \mathrm{~nm}$ for the films shown in Fig. 2a, Fig. 2b, and Fig. 2c, respectively. Thus, one can conclude that dip-coating represents a method with a reduced efficiency of the CuPc film formulation (coverage), however, with a very good control of the film surface texture.

For the structures observed in spin-casted films, the Ra was found to be $0.3 \pm 0.1 \mathrm{~nm}, 1.1 \pm 0.1 \mathrm{~nm}$, and $1.4 \pm 0.2 \mathrm{~nm}$ for samples shown in Fig. 3a, Fig. 3b, and Fig. 3c, respectively. We have analyzed the surface morphology and topography of the studied specimens for the largest accessible scan area (approx. $100 \mu \mathrm{m} \times 100 \mu \mathrm{m})$ and obtained homogeneous surfaces of the films, as well. For highly homogeneous surfaces with continuous surface texture Ra can be taken as a global (macro) component that describes a topological character of the surface and its structure. The $\mathrm{S}_{\mathrm{CuPc}}$ values for multilayer films are found to be $\sim 85 \%$, which is the maximum coverage that can be obtained in CuPc spin-casted films, even if the entire film continues to grow with the increasing solution concertation applied for the deposition $\left(\mathrm{V}_{\mathrm{CuPc}}\right.$ in Table 1).

For spray-coated films, Ra was found to be significant, i.e. $1.3 \pm 0.2 \mathrm{~nm}, 6.1 \pm 1.3 \mathrm{~nm}$, and $8.1 \pm 1.7 \mathrm{~nm}$ for structures shown in Fig. 4a, Fig. $4 \mathrm{~b}$ and Fig. 4c, respectively. The sample morphology and topography presented in Fig. $4 \mathrm{~b}$ and Fig. $4 \mathrm{c}$ as well as the values of the surface texture components (Table 1) suggest the studied specimens as valuable and promising for an organic solar cell (OSC) preparation. The properties observed and values calculated meet the requirements for effective charge transfer as the diffusion length of excitons before recombination in OSCs bilayers is $10 \mathrm{~nm}$ to $20 \mathrm{~nm}[57,58]$. Furthermore, the direction of $\mathrm{CuPc}$ molecular stacking axis should be diversified, preferentially with molecules that are lying down with respect to the surface (high angle of inclination of the molecular plane with respect to the substrate), to maximize charge transport (in the direction between two electrodes) [59]. This seems to be introduced by the rod-like features obtained by the spray-coating. The film volume can also be obtained as the highest (e.g. $1.04 \mu^{3}$ ) compared to 

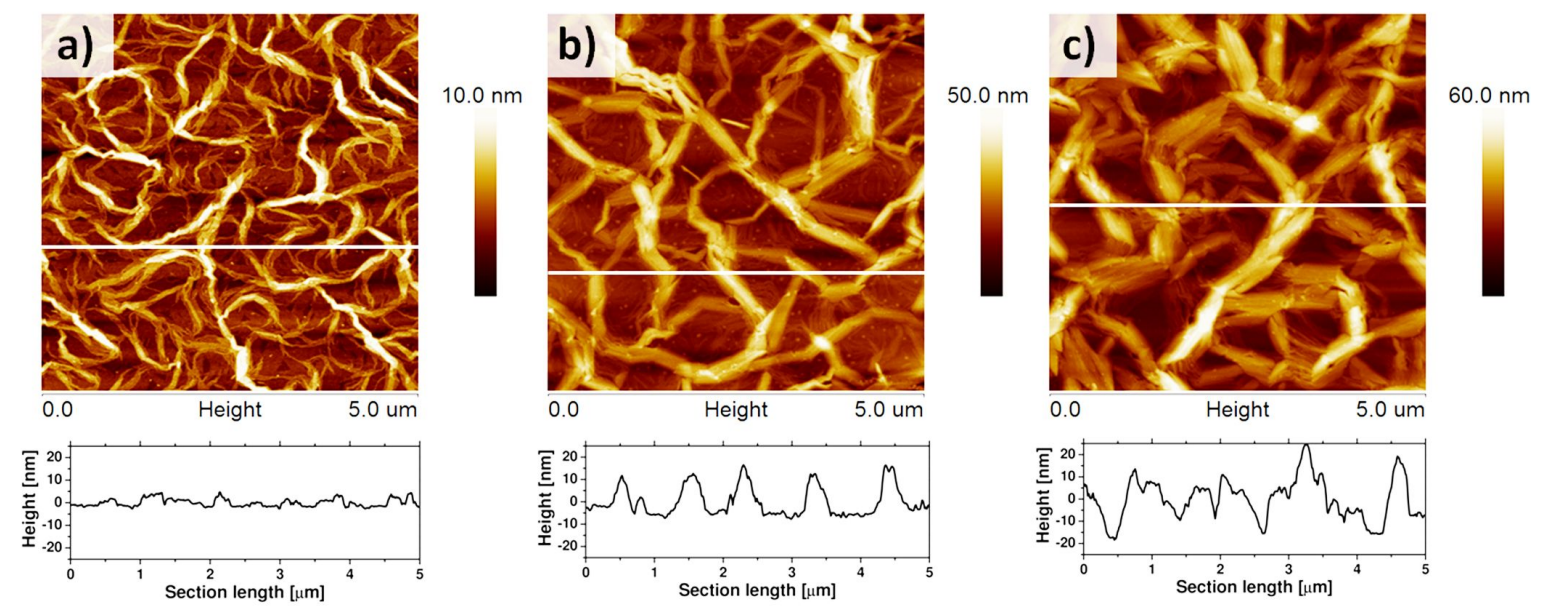

Fig. 4. AFM height images of spray-coated films from $\mathrm{CuPc}$ /TFA solution on $\mathrm{SiO}_{2}$ substrate after 1 deposition cycle (a), 3 deposition cycles (b), and 5 deposition cycles with the interval time of $30 \mathrm{~s}$ between cycles (c). Each cycle took $10 \mathrm{~s}$. The concentration of solution used: $1.5 \times 10^{-3} \mathrm{~mol} \cdot \mathrm{L}^{-1}$. White lines represent section lines with their respective section plots. The height scale in the section plots is adjusted to make the data comparable.

other solution processing methods discussed in this work. Interestingly, the substrate coverage fraction can reach almost $\sim 97 \%$. We attribute this fact to a disturbed mesh-like (nanoribbon) growth in the first $\mathrm{CuPc}$ layer that is adsorbed on the silicon substrate. In the order mesh-like growth, the fraction of the substrate, which is not covered by the $\mathrm{CuPc}$ molecules is minimum $\sim 15 \%$ [45].

\section{Raman mapping}

Although reports on spin-casted $\mathrm{CuPc}$ films used for OSC preparation are virtually nonexisting [44, 47], it is commonly known that the $\mathrm{CuPc}$ orientation in the donor layer and at the interface (connection line with the acceptor layer) are of a high importance to optimize processes required for high energy conversion in OSCs [60]. The power conversion efficiency in CuPc-based OSCs was found to be increasing with the increasing angle of inclination of the molecular plane with respect to the substrate, $\beta_{\mathrm{CuPc}}$ [59].

We note that the rewetting effects in spincasting of small molecules are often neglected; if not indicated otherwise, spin-casting should be performed only with one droplet placed on a substrate. This is not always preserved, resulting in (1) an increased coverage and (2) feasible morphological and structural changes in deposited films [5, 6163]. Subsequent deposited droplets of an unsaturated solution dissolve the existing film; the efficiency of that effect is an interplay, particularly, between the speed of rotation, solvent evaporation rate and molecular solubility [5, 63, 64]. Thermal annealing is also known to boost the molecular order in the CuPc films [39, 65]. Thus, for spin-coated CuPc films we compared two treatments that influence the molecular order, particularly $\beta_{\mathrm{CuPc}}$, namely the film rewetting (second droplet deposition) and the long-term annealing $(5 \mathrm{~h})$ at $150{ }^{\circ} \mathrm{C}$. In order to study 3-dimentional aspects of the $\beta_{\mathrm{CuPc}}$ variation, the Raman micromaps were recorded and evaluated.

Fig. 5 shows unpolarized Raman spectra for spin-casted $\mathrm{CuPc}$ films deposited from 1 drop and 2 drops of $0.7 \times 10^{-3} \mathrm{~mol} \cdot \mathrm{L}^{-1}$ solution, respectively. On the Raman spectrum, we observe the most intense ( $B_{1 g}$ symmetry) band at about $1529 \mathrm{~cm}^{-1}$, which is closely linked to metal ion $(\mathrm{Cu})$ adapted to phthalocyanine molecule. This band is characterized by the displacement of $\mathrm{C}-\mathrm{N}-\mathrm{C}$ bridge bonds of the phthalocyanine macrocycle [66]. Such property can be 
Table 1. The mean roughness, $\mathrm{Ra}$, the substrate coverage fraction, $\mathrm{S}_{\mathrm{CuPc}}$, and the film volume, $\mathrm{V}_{\mathrm{CuPc}}$, for $\mathrm{CuPc}$ films deposited by solution processing methods from TFA solvent.

\begin{tabular}{|c|c|c|c|c|c|}
\hline \multirow{2}{*}{$\begin{array}{c}\text { Solution } \\
\text { concentration } \\
{\left[\mathrm{mol} \cdot \mathrm{L}^{-1}\right]}\end{array}$} & \multirow{2}{*}{$\begin{array}{l}\text { Surface } \\
\text { texture } \\
\text { compo- } \\
\text { nents }\end{array}$} & \multicolumn{4}{|c|}{ Method } \\
\hline & & Drop-casting & Dip-coating & $\begin{array}{l}\text { Spin- } \\
\text { casting }\end{array}$ & Spray-coating \\
\hline \multirow{3}{*}{$0.5 \times 10^{-3}$} & $\mathrm{Ra}[\mathrm{nm}]$ & - & $0.4 \pm 0.1$ & $0.3 \pm 0.1$ & - \\
\hline & $\mathrm{S}_{\mathrm{CuPc}}[\%]$ & - & 17.6 & 71.2 & - \\
\hline & $\begin{array}{l}\mathrm{V}_{\mathrm{CuPc}} \\
{\left[{\left.\mu \mathrm{m}^{3}\right]}^{3}\right.}\end{array}$ & - & 0.012 & 0.028 & - \\
\hline \multirow{3}{*}{$1.0 \times 10^{-3}$} & $\mathrm{Ra}[\mathrm{nm}]$ & - & $0.6 \pm 0.1$ & $1.1 \pm 0.1$ & - \\
\hline & $\mathrm{S}_{\mathrm{CuPc}}[\%]$ & - & 37.5 & 84.5 & - \\
\hline & $\begin{array}{l}\mathrm{V}_{\mathrm{CuPc}} \\
{\left[{\left.\mu \mathrm{m}^{3}\right]}\right]}\end{array}$ & - & 0.024 & 0.096 & - \\
\hline \multirow[t]{3}{*}{$1.5 \times 10^{-3}$} & $\mathrm{Ra}[\mathrm{nm}]$ & $\begin{array}{l}0.9 \text { (spot a) } \\
9.7(\text { spot b) } \\
5.5(\text { spot c }) \\
\end{array}$ & $0.5 \pm 0.1$ & $1.4 \pm 0.2$ & $\begin{array}{l}1.3 \pm 0.2(1 \text { cycle }) \\
6.1 \pm 1.3(3 \text { cycles }) \\
8.1 \pm 1.7(5 \text { cycles })\end{array}$ \\
\hline & $\mathrm{S}_{\mathrm{CuPc}}[\%]$ & $\begin{array}{l}60.9(\text { spot a) } \\
68.0(\text { spot } b) \\
82.4(\text { spot } c)\end{array}$ & 64.4 & 85.8 & $\begin{array}{l}87.4 \text { ( } 1 \text { cycle }) \\
92.3 \text { ( } 3 \text { cycle }) \\
96.9(5 \text { cycle })\end{array}$ \\
\hline & $\begin{array}{l}V_{\mathrm{CuPc}} \\
{\left[{\left.\mu \mathrm{m}^{3}\right]}^{3}\right]}\end{array}$ & $\begin{array}{l}0.072 \text { (spot a) } \\
0.892 \text { (spot b) } \\
0.652 \text { (spot c) }\end{array}$ & 0.036 & 0.132 & $\begin{array}{l}0.104(1 \text { cycle }) \\
0.696(3 \text { cycle }) \\
1.040(5 \text { cycle })\end{array}$ \\
\hline
\end{tabular}

useful as a marker for distinguishing a different metallophthalocyanine thin film, with different metal ion on the center of molecule.

Analysis of the integral intensity of the bands obtained for different polarized Raman spectra gives information about the molecular orientation, particularly $\beta_{\mathrm{CuPc}}$. Fig. 6 presents polarized Raman spectra of a sample obtained as a result of rewetting with a second solution drop. A change in the intensity of the polarized Raman bands is observed. A suitable change in the intensity of the $\mathrm{B}_{1 \mathrm{~g}}$ bands (at $1529 \mathrm{~cm}^{-1}$ ) is related to the type of the polymorphic forms of the metallophthalocyanine thin layers. The averaged intensity of this band in parallel polarization of incident and scattered light $\left(\mathrm{I}_{\mathrm{VV}}\right)$ as well as in cross polarization of incident and scattered light $\left(\mathrm{I}_{\mathrm{VH}}\right)$ can be described by the following equation:

$$
\frac{I_{V V}}{I_{V H}}=2 \frac{\cos ^{2} \beta_{C u P c}}{\sin ^{2} \beta_{C u P c}}
$$

Raman mapping consisted of producing Raman spectra (point by point) in the selected area, in two different scattering geometries of light (VV and $\mathrm{VH}$ ), and determining, in each studied point, the integral intensity of the selected Raman band (at $1529 \mathrm{~cm}^{-1}$ ). Then, using equation 1 , in each of the examined points, the angle between the molecule and substrate was obtained. On this basis, the distribution of angles between molecules and substrate in the analyzed area of the sample was determined. Detailed information concerning the designation of orientation of the metallophthalocyanine thin layers using polarized Raman spectra we concluded in our previous work [40].

Raman mapping, i.e. two Raman maps with $\mathrm{VV}$ and $\mathrm{VH}$ polarization, gives information about distribution of the polymorphic form of $\mathrm{CuPc}$ thin layers (Fig. 7). In Fig. 7, $\beta_{\mathrm{CuPc}}$ ranges from $42^{\circ}$ to $55^{\circ}$ and from $33^{\circ}$ to $51^{\circ}$ for samples spin-casted with 1 drop and 2 drops, respectively, 


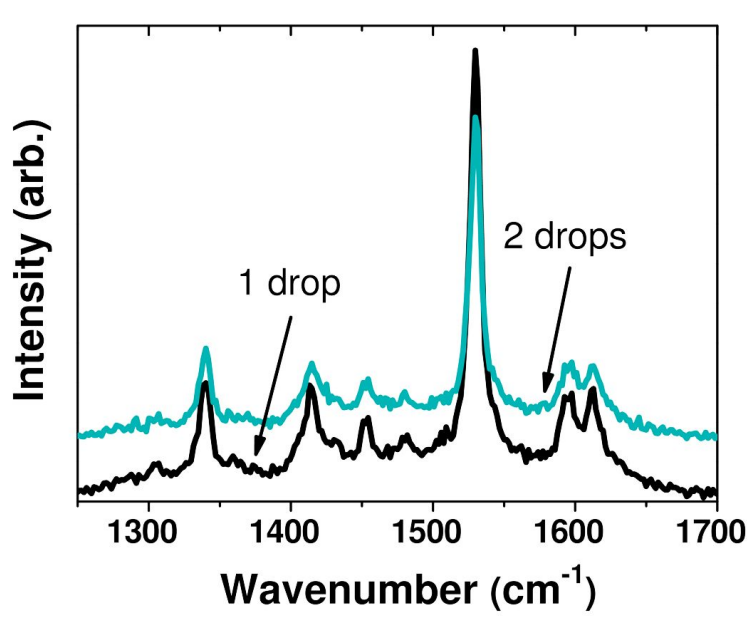

Fig. 5. Unpolarized Raman spectra. Samples prepared by spin-casting CuPc/TFA solution $\left(7.0 \times 10^{-4} \mathrm{~mol} \cdot \mathrm{L}^{-1}\right)$ at $5000 \mathrm{rpm}$ on $\mathrm{SiO}_{2}$. Numbers of drops placed on the substrate are indicated.

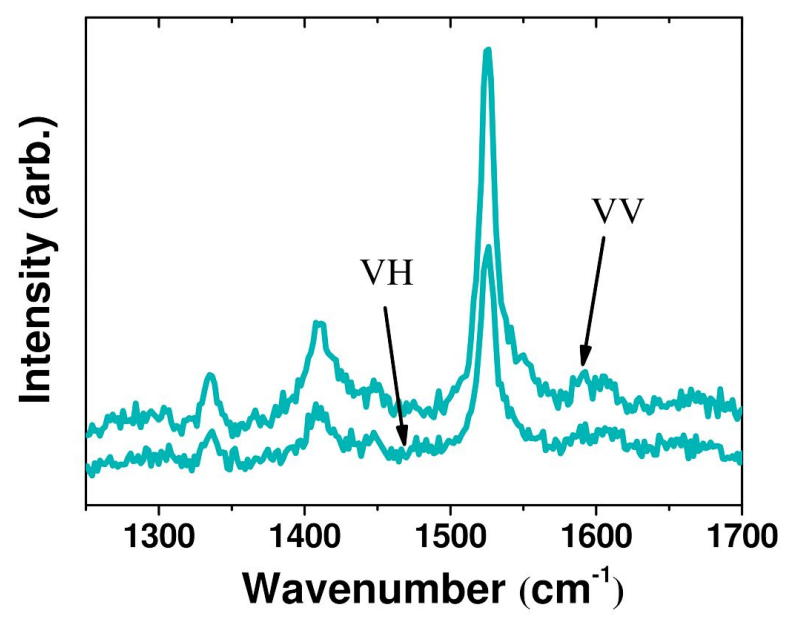

Fig. 6. Polarized Raman spectra of spin-casted CuPc film prepared by 2 drops deposition on $\mathrm{SiO}_{2}$.

with an average $\beta_{\mathrm{CuPc}}$ value of $50^{\circ}$ and $42^{\circ}$. These data are collected in the Table 2 . Although the averaged $\beta_{\mathrm{CuPc}}$ value indicates the existence of a stable $\beta$-phase for both samples, the analysis of the maps clearly indicates a decrease of the angle of inclination of the CuPc plane with respect to the substrate after rewetting. This presumably can lower power conversion efficiency in as-designed OSCs as the molecules are "standing-like" on the surface [59].

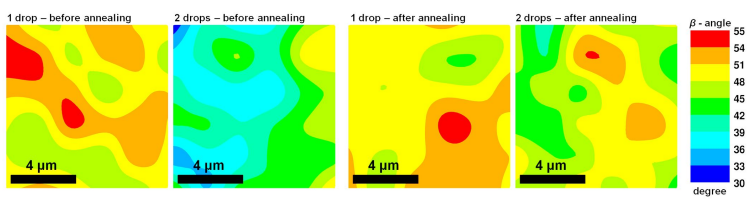

Fig. 7. Raman maps of spin-casted $\mathrm{CuPc}$ films deposited with 1 drop and 2 drops on $\mathrm{SiO}_{2}$, thereafter annealed at $150{ }^{\circ} \mathrm{C}$ for $5 \mathrm{~h}$.

The annealing treatment has not affected spincoated films obtained by 1 drop-processing. $\beta_{\mathrm{CuPc}}$ changed from $45^{\circ}$ to $55^{\circ}$ in this case with an average of $50^{\circ}$. It seems that for such a thin film a more homogeneous structure cannot be obtained. The film made of 2 solution droplets contains at least one additional layer of $\mathrm{CuPc}$ molecules as compared to its 1 drop-processed counterpart. Thus, it is more prone to molecular reorganization; $\beta_{\mathrm{CuPc}}$ changes from $41^{\circ}$ to $54^{\circ}$ in this case with an average of $47^{\circ}$.

\section{Conclusions}

This article highlights structural picture of thin $\mathrm{CuPc}$ films deposited on planar $\mathrm{SiO}_{2}$ surfaces by solution processing methods, namely drop-casting, dip-coating, spin-casting, and spraycoating at room temperature from highly concentrated $\mathrm{CuPc}$ in TFA compositions. The indisputable advantage of the solution processing methods addresses considerably less equipment and is less expensive as compared with convectional vacuumbased techniques. We show detailed AFM imaging and morphological analysis, supported by $\mu$ Raman mapping, to unveil the criteria for $\mathrm{CuPc}$ film architecture. The obtained results indicate a noticeable influence of the solution processing method on the morphology, topography (film thickness), preferred molecular orientation and distribution of polymorphic phase in CuPc thin film. Dipcoating, spin-casting and 1 cycle spray-coating provide similar features in the film (pyramidal growth of nanoribbons), whereas multicycle spray-coating leads to a rod-like structure composed of CuPc crystals. The absence of gravitational and centrifugal forces (drop-casting and spray-coating) leads to enhancing the film thickness. Drop-casted film 
Table 2. Average angles between molecules and substrate before and after annealing of spin-casted CuPc film.

\begin{tabular}{lll}
\hline Wetting (spin-casting) & No annealing & Annealed at $150^{\circ} \mathrm{C}$ for $5 \mathrm{~h}$ \\
\hline \hline 1 drop & $50^{\circ}$ & $50^{\circ}$ \\
2 drops & $42^{\circ}$ & $47^{\circ}$ \\
\hline
\end{tabular}

are not homogeneous. The Raman mapping shows that although the multiple coating in spin-coating leads to deterioration of the molecular order in the $\mathrm{CuPc}$ films, the post-annealing may undo the original order. Our findings should be taken in consideration, when designing CuPc molecular architecture for thin film applications.

\section{Acknowledgements}

H.G. and M.S. thank the Ministry of Science and Higher Education in Poland for financial support as well as for the project no. 650/MOB/2011/10. H.G. thanks the Max Planck Institute of Colloids and Interfaces for the access to the AFM lab. We are also thankful to MSc. Lehani Verwey from the University of Twente for language proofreading of the manuscript and valuable remarks.

\section{References}

[1] Swalen J.D., Allara D.L., Andrade J.D., Chandross E.A., Garoff S., IsraelachVili J., McCarthy T.J., Murray R., PeAse R.F., Rabolt J.F., Wynne K.J., YU H., Langmuir, 3 (1987), 932.

[2] Seshan K., Handbook of Thin Film Deposition: Techniques, Processes, and Technologies, $3^{\text {rd }}$ Ed., Elsevier, 2012.

[3] Martin P.M. (Ed.), Handbook of Deposition Technologies for Films and Coatings, Elsevier, 2010.

[4] Mitzi D.B. (Ed.), Solution Processing of Inorganic Materials, Wiley, 2008.

[5] Yang Y., Li G. (Ed.), Progress in High-Efficient Solution Process Organic Photovoltaic Devices: Fundamentals, Materials, Devices and Fabrication, Springer, 2015.

[6] Gojzewski H., Makowski M., Hashim A., KopCANSKY P., TOMORI Z., TIMKO M., Scanning, 34 (2012), 159.

[7] Morrin A., Wilbeer F., Ngamna O., Moulton S.E., Killard A.J., Wallace G.G., SMYth M.R., Electrochem. Commun., 7 (2005), 317.

[8] Choi H., Stathatos E., Dionysiou D.D., Appl. Catal. B, 63 (2006), 60.

[9] Caldeira L., VAsconcelos D.C.L., NunES E.H.M., Costa V.C., Musse A.P., Hatimondi S.A., NASCIMENTO J.F., GRAVA W., VASCONCELOS W.L., Ceram. Int., 38 (2012), 3251.

[10] Bormashenko E., Pogreb R., Stanevsky O.,
Bormashenko Y., Stein T., Gaisin V.Z., CoHen R., Gendelman O.V., Macromol. Mater. Eng., 290 (2005), 114.

[11] Chang D., Yoon D., Ro M., Hwang I., Park I., Shin D., Jpn. J. Appl. Phys., 42 (2003), 754.

[12] Lindgren L.J., Zhang F., ANdersson M., BARrau S., Hellstrom S., Mammon W., Perzpn E., Inganaes O., Andersson M.R., Chem. Mater, 21 (2009), 3491.

[13] Nohria R., Khillan R.K., Su Y., Dikshit R., Lvov Y., Varahramyan K., Sensor. Actuator. B, 114 (2006), 218.

[14] Sirringhaus H., Adv. Mater, 17 (2005), 2411.

[15] Chang J.F., Sun B., Breiby D.W., Nielsen M.M., Soelling T.I., Giles M., MCCulloch I., SiRRINGHAUs H., Chem. Mater., 16 (2004), 4772.

[16] Shi Y., LiU J., Yang Y., J. Appl. Phys., 87 (2000), 4254.

[17] PU Y.J., Higashidate M., NAKAYAMA K.I., KIDO J., J. Mater. Chem., 18 (2008), 4183.

[18] Kobayashi H., Kanbe S., Seki S., Kigchi H., Kimura M., Yudasaka I., MiYashita S., ShIMOdA T., TOWns C.R., Burroughes J.H., FriEnd R.H., Synth. Met., 111 (2000), 125.

[19] Gray J.E., Luan B., J. Alloy. Compd., 336 (2002), 88.

[20] Wu W., WAng X., LiU X., Zhou F., ACS Appl. Mater. Int., 1 (2009), 1656.

[21] Krogman K.C., Lowery J.L., Zacharia N.S., Rutledge G.C., Hammond P.T., Nature Mater, 8 (2009), 512.

[22] Men X., Zhang Z., Yang J., Zhu X., Wang K., JIANG W., New J. Chem., 35 (2011), 881.

[23] JAFARI S.M., ASSADPOOR E., Bhandari B., HE Y., Food Res. Int., 41 (2008), 172.

[24] Alamilla-Beltran L., Chanona-Perez J.J., JimenEZ-APARICIO A.R., GUTIEREZ-LOPEZ G.F., J. Food Eng., 67 (2005), 179.

[25] Girotto C., Rand B.P., Genoe J., Heremans P., Sol. Energ. Mat. Sol. C., 93 (2009), 454.

[26] Wolz A., Zils S., Michel M., Roth C., J. Power Sources, 195 (2010), 8162.

[27] Rajeshmon V.G., Kartha C.S., ViJayaKumar K.P., Sanjeeviraja C., Abe T., Kashiwaba Y., Sol. Energ., 85 (2011), 249.

[28] Kadish K.M., SMith K.M., Gillard R. (Ed.), The Porphyrin Handbook, Academic Press, San Diego, 2000.

[29] YAng F., Forrest S.R., ACS Nano, 2 (2008), 1022.

[30] Huang Y.S., Jou J.H., Weng W.K., LiU J.M., Appl. Phys. Lett., 80 (2002), 2782. 
[31] Ye R., Baba M., Oishi Y., Mori K., SuzuKi K., Appl. Phys. Lett., 86 (2005), 1.

[32] Inabe T., Tajima H., Chem. Rev., 104 (2004), 5503.

[33] Peumans P., Forrest S.R., Appl. Phys. Lett., 79 (2001), 126.

[34] Tang Q., Li H., He M., Hu W., Liu C., Chen K., WANG C., LIU Y., ZHU D., Adv. Mater., 18 (2006), 65.

[35] Kumawat L.K., Mergu N., Singh A.K., Gupta V.K., Sensor. Actuator. B, 212 (2015), 389.

[36] Gomez de Arco L., Zhang Y., Schlenker C.W., Ryu K., Thompson M.E., Zhou C., ACS Nano, 4 (2010), 2865.

[37] Jha A., Ghorai U.K., Banerjee D., MukherJeE S., Chattopadhyay K.K., RSC Adv, 3 (2013), 1227.

[38] Chunder A., Pal T., Khondaker S.I., Zhai L., $J$. Phys. Chem. C, 114 (2010), 15129.

[39] Szybowicz M., Bala W., Fabisiak K., PaPROCKI K., DrozdowsKi M., J. Mater. Sci., 46 (2011), 6589.

[40] Szybowicz M., Runka T., Drozdowski M., BALA W., Grodzicki A., PiszczeK P., Bratkowski A., J. Mol. Struct., 704 (2004), 107.

[41] Huang H., Chen W., Chen S., Qi D.C., Gao X.Y., WeE A.T.S., Appl. Phys. Lett., 94 (2009), 163304.

[42] Bobisch C., Wagner T., Bannani A., Moeller R., J. Chem. Phys., 119 (2003), 9804.

[43] Komino T., Matsuda M., Tajima H., Thin Solid Films, 518 (2009), 688.

[44] Ghani F., Bochukov I., Fostiropoulos K., RIEGLER H., Thin Solid Films, 525 (2012), 177.

[45] Ghani F., Gojzewski H., Riegler H., Appl. Surf. Sci., 351 (2015), 969.

[46] Afify H.A., Gadallah A.S., El-Nahass M.M., ATtA KHedr M., J. Mol. Struct., 1098 (2015), 161.

[47] Lin W.K., Su S.H., LiU C.C., Yokoyama M., Jpn. J. Appl. Phys., 53 (2014), 11RB04.

[48] Ghani F., Kristen J., Riegler H., J. Chem. Eng. Data, 57 (2012), 439.

[49] Grosso D., J. Mater. Chem., 21 (2011), 17033.

[50] Dobre M., Bolle L., Exp. Therm. Fluid Sci., 26 (2002), 205.

[51] Gojzewski H., Richter A., Wrobel D., Apos-
Toluk A., Siejak P., Raimond P., Surf. Sci., 603 (2009), 237.

[52] Szybowicz M., Bala W., Duemecke S., FABISIAK K., PAPROCKI K., DROZDOWSKI M. Thin Solid Films, 520 (2011), 623.

[53] Hoshino A., Takenaka Y., Miyaji H., Acta Cryst. $B, 59$ (2003), 393.

[54] Deegan R.D., BaKajin O., Dupont T.F., HuBer G., NAgel S.R., WitTen T.A., Nature, 389 (1997), 827.

[55] Ghani F., Max Planck Institute of Colloid and Interfaces, Potsdam, 2012.

[56] Brinker C.J., Frye G.C., Hurd A.J., Ashley C.S., Thin Solid Films, 201 (1991), 97.

[57] Guenes S., Neugebauer H., Sariciftci N.S., Chem. Rev., 107 (2007), 1324.

[58] Brabec C.J., Durrant J.R., MRS Bull., 33 (2008), 670.

[59] Sullivan P., Jones T.S., Ferguson A.J., Heutz S., Appl. Phys. Lett., 91 (2007), 233114.

[60] Rand B.P., Cheyns D., VAsseur K., Giebink N.C., Mothy S., Yi Y., Coropceanu V., Beljonne D., Cornil J., Brédas J.L., Genoe J., Adv. Funct. Mater., 22 (2012), 2987.

[61] Chen T.L., Chen J.J.A., Catane L., Ma B., Org. Electron., 12 (2011), 1126.

[62] Schubert D.W., Dunkel T., Mater. Res. Innov., 7 (2003), 314.

[63] Karpitschka S., Weber C.M., Riegler H., Chem. Eng. Sci., 129 (2015), 243.

[64] Mokarian-Tabari P., Geoghegan M., Howse J.R., HERIOT S.Y., THOMPSON R.L., JONES R.A.L., Eur. Phys. J. E, 33 (2010), 283.

[65] Gaffo L., Cordeiro M.R., Freitas A.R., MorEIRA W.C., GirotTo E.M., ZuCOLOTTO V., J. Mater. Sci., 45 (2010), 1366.

[66] Tackley D.R., Dent G., Smith W.E., Phys. Chem. Chem. Phys., 3 (2001), 1419.

Received 2018-06-14 Accepted 2019-04-23 